\title{
Inventory of infections related to central venous catheters in a Moroccan medical resuscitation department
}

\author{
Ezzouine H., Dghoughi S., Benslama A. \\ Medical intensive care unit \\ Dept of Anaesthesiology \& Intensive Care, \\ University Hassan II Faculty of Medicine and Pharmacy, \\ Casablanca, Morocco
}

Background and Goal of Study:

Central venous catheters (CVCs) are very commonly used in intensive care.

Catheter related infection (CRI) is the leading complication and the second leading cause of nosocomial infections in intensive care. -This work is a descriptive and analytical retrospective study of documented infections related to the central venous catheters, spread over a period of one year, from January 2015 to December 2015, carried out in the medical resuscitation department of the Ibn Rushd Hospital in Casablanca, Morocco . Its objective is to determine the incidence and microbiological profile of CRIs.

Materials and Methods:

Included were all patients with central venous catheterization, with or without bacteraemia, after hospitalization in the medical resuscitation unit of Ibn Rushd Hospital for more than 48 hours.

Results and Discussion:

-The incidence rate was $6.78 \%$ with a female predominance of $51.9 \%$.

-Gram negative bacilli were the most frequently isolated germs $40.5 \%$ with the top of the list

Acinetobacter Baumanii and Klebsiella pneumoniae with an equal rate of $26.6 \%$,

-followed by gram positive cocci $35.1 \%$ represented by staphylococci coagulase Negative $84.6 \%$.

-The yeasts were found in $18.5 \%$ of the cases.

The majority of the patients presented with a single germ: $74.1 \%$. The association of germs was found in $25.9 \%$ of the cases, dominated by the association of 2 germs

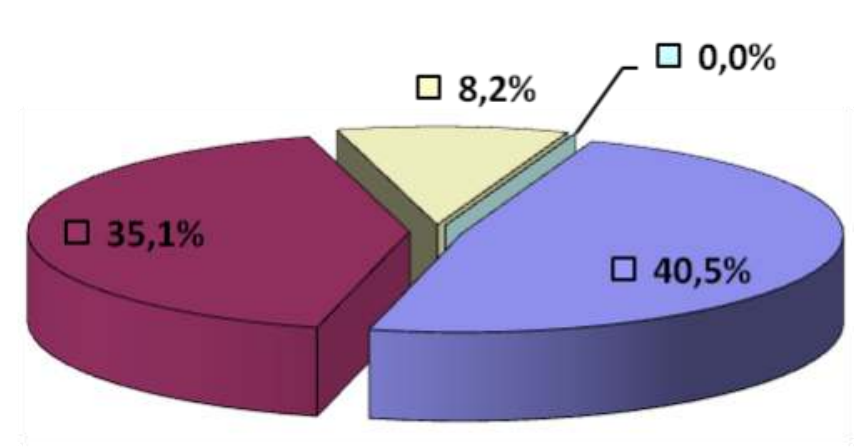

\begin{tabular}{|lll|} 
Germ & N & Pourcentage \\
\hline $\begin{array}{l}\text { Acinetobacter } \\
\text { Baumannii }\end{array}$ & 4 & $26,67 \%$ \\
\hline Klebsiella pneumoniae & 4 & $26,66 \%$ \\
\hline Proteus mirabilis & 2 & $13,33 \%$ \\
\hline $\begin{array}{l}\text { Pseudomonas } \\
\text { aeruginosa }\end{array}$ & 2 & $13,34 \%$ \\
\hline Klebsiella terrigena & 1 & $6,67 \%$ \\
\hline Enterobacter cloacae & 1 & $6,67 \%$ \\
\hline Serratia marcescens & 1 & $6,66 \%$ \\
\hline
\end{tabular}

\begin{tabular}{|lll|}
\hline Germ & N & Pourcentage \\
\hline Staphylocoque aureus & 2 & $15,39 \%$ \\
\hline $\begin{array}{l}\text { Staphylocoque } \\
\text { coagulase negative }\end{array}$ & 10 & $84,61 \%$ \\
\hline
\end{tabular}

Conclusion(s):

Acinetobacter Baumanii and klebsiella pneumoniae are the main germ associated to catheter related infection in our unit.

It is important to note that the lack of information on the CVC application files is a factor in the proper followup of these infections. Indeed, a checklist must be used as a "memo tool" which will make it possible to secure the installation of the CVC and to minimize risks related to human hazard. 